Documentación de las Ciencias de la Información ISSN: 0210-4210

http://dx.doi.org/10.5209/DCIN.61411

\title{
Revistas, diarios y prensa gratuita en España. Revisión y nuevas perspectivas del patrimonio documental en la prensa
}

\author{
Antonia Salvador Benítez'; María Olivera Zaldua²; Juan Miguel Sánchez Vigil ${ }^{3}$
}

Enviado: 28 de agosto de 2018 / Aceptado: 10 de septiembre de 2018

Resumen. La documentación generada o relacionada con la prensa, incluidos las propias publicaciones, constituyen un corpus excepcional por su cantidad y calidad. Su conservación y tratamiento analítico es fundamental para la recuperación de contenidos. La hemeroteca es por tanto, siempre lo fue, una fuente de información por excelencia. Siendo así, es fácil de entender que forme parte del patrimonio documental de los medios de comunicación, junto con el televisivo, radiofónico, cinematográfico y publicitario, y que como tal patrimonio debe ser tratado siguiendo los protocolos y normativas al efecto. Es objeto de este trabajo ofrecer una visión general sobre la situación del patrimonio documental de la prensa, teniendo en cuenta el desarrollo histórico de la misma. Se describen y analizan los principales problemas que se afrontan tomando como muestra y modelo las revistas, diarios y prensa gratuita editados en España.

Palabras clave: Patrimonio hemerográfico; hemeroteca digital; diarios; revistas: prensa gratuita; documentación informativa; fuentes de información

\section{[en] Magazines, newspapers and free dailies in Spain. Review and new perspectives on press documentary heritage}

\begin{abstract}
The documentation produced or related to the press, including the publications themselves, make up an exceptional corpus due to their quality and quantity. Their conservation and analytical study is fundamental for the recovery of their valuable contents. The Hemeroteca (Newspaper and Periodicals Library) is, then, and always was the par excellence source of information. As this is the case, it is easy to understand that it forms a part of the documentary patrimony of the communications media, together with the television, radio, cinema and advertising archives. And as such a patrimony, it must be managed in accordance with the protocols and regulations established for this purpose. The purpose of this study is to offer an overview of the situation of the documentary patrimony of the press, bearing in mind its historical development. The main problems are described and analyzed, by adopting the magazines, daily newspapers and press published for free distribution in Spain as an example and a model.

Keywords: Newspaper and periodicals patrimony; daily newspapers; magazines; press for free distribution; informative documentation; sources of information
\end{abstract}

Sumario: 1. Introducción. 2. Los diarios. 2.1. Versiones digitales. 2.2. Blogs y redes. 3. Las revistas. 3.1. La crisis de las clásicas. 3.2. La especialización. 3.3. Una mirada al futuro. 4. La prensa gratuita.

1 Facultad de Ciencias de la Documentación, Universidad Complutense de Madrid asalvado@ucm.es

2 Facultad de Ciencias de la Documentación, Universidad Complutense de Madrid molivera@ucm.es

3 Facultad de Ciencias de la Documentación, Universidad Complutense de Madrid jmvigil@ucm.es 
4.1. Madridy m@s, 20 Minutos, Metro, Qué! y ADN. 4.2. Crisis del sector. 5. La prensa en las hemerotecas. 6. El Archivo de la Web Española. 7. Conclusiones. 8. Bibliografía.

Cómo citar. Salvador Benítez, A.; Olivera Zaldua, M.; Sánchez Vigil, J.M. (2018) Revistas, diarios y prensa gratuita en España. Revisión y nuevas perspectivas del patrimonio documental en la prensa en Documentación de las Ciencias de la Información 41, 147-161.

\section{Introducción}

En el estudio y análisis de la evolución de la prensa, las teorías son muchas y controvertidas, desde las que vaticinaron la muerte inmediata de la prensa impresa frente a la digital, hasta las que se aferraron a los modelos clásicos menospreciando el mundo digital y globalizador. Los medios de comunicación, blogs y redes sociales hacen referencia a la desaparición de la prensa impresa a partir de primera década del siglo XXI, así como a los cambios y a las nuevas perspectivas derivadas de su evolución. Al tiempo que se cerraban muchas cabeceras, a veces de manera precipitada y por razones no justificadas por cuestiones económicas sino estratégicas, los periódicos eran incorporados a las hemerotecas digitales, para cumplir con su imprescindible función como fuente. Por otra parte las instituciones públicas tomaban conciencia de la necesidad de conservar los periódicos para su consulta, caso de la Hemeroteca Digital de la Biblioteca Nacional de España, la Hemeroteca Municipal de Madrid o la de la Fundación Pablo Iglesias, entre muchas otras, y algunas empresas de comunicación también entendieron la rentabilidad en esa línea, como los históricos diarios El Norte de Castilla, La Vanguardia o ABC.

Es objeto de este trabajo ofrecer una visión general sobre la situación de la documentación de la prensa, considerada patrimonio, teniendo en cuenta su desarrollo histórico. Se describen y analizan algunos de los problemas que se afrontan, tomando como muestra y modelo tres grupos diferenciados: revistas, diarios y prensa gratuita. Como método, además de la revisión bibliográfica sobre el tema, se han recuperado entrevistas con editores y directores de las publicaciones, se han analizado las causas del cierre de empresas y, al mismo tiempo, la creación de proyectos digitales.

Cada publicación tiene características determinantes con las que ha mantenido o fidelizado el interés de los usuarios, un fenómeno que cambió con Internet, es decir, con el medio y no con el contenido, y es precisamente el medio el que ha condicionado la presentación y el fondo. La ingente cantidad de documentos generados por la prensa, y las propias publicaciones, constituyen la base del "cuarto poder", como la denominara Edmund Burke en el debate de apertura de la Cámara de los Comunes del Reino Unido en 1787.

El estado de la cuestión sobre el tema que tratamos presenta una situación ciertamente interesante si tenemos en cuenta la documentación generada por las publicaciones y de la que no se tienen referencias de su conservación y tratamiento. Sobre la prensa digital son de relevancia los textos de Cerezo Gilarranz (2009) y Delgado Barrera (2009). En cuanto a la historia de las revistas, Angeletti y Oliva (2002) seleccionaron ocho cabeceras, justificando su presencia por la estructura, gestión o contenidos (Time, Deer Spiegel, Life, París Match, National Geographic, Reader's Digest, ;Hola! y People) y en cada caso estudiaron la fórmula de su éxito, así Deer Spiegel "agregó la investigación y la aclaración crítica, convirtiéndose en una publicación contestaría, polémica y prestigiosa", People "revolucionó el llamado perio- 
dismo de la personalidad, añadiendo interés humano a las historias", y ¡Hola "fue fundamental para el crecimiento del segmento de revistas de celebridades".

Las fuentes para el estudio del tema han sido la propia prensa, cuyas referencias se recogen en la bibliografía, el Libro Blanco de la Prensa (2016), los datos del Estudio General de Medios (2016) y de los Informes Anuales de la Profesión Periodística (2016).

En lo que se refiere a la prensa gratuita se han realizado estudios sobre el modelo de negocio (Arroyo Cabello, 2006; Martínez Soler, 2006), la calidad informativa (Casero Ripollés, 2002; Flores Vivar y Mirón López, 2009), la evolución del mercado (Remón, 2006; Ramón, 2009) o la saturación publicitaria (Martínez Guillén, 2012). De especial referencia es el estudio de Gómez Quijano (2016) por la actualidad y la profundidad del análisis de las principales cabeceras españolas.

Fundamentales han sido también para datos específicos las hemerotecas digitales de la Biblioteca Nacional de España y del Ayuntamiento de Madrid, así como las de los diarios $A B C$ y La Vanguardia, entre otros, y el Archivo de la Web Española de la Biblioteca Nacional de España.

\section{Los diarios}

Las primeras experiencias digitales en España las pusieron en marcha los diarios Avui y El Periódico de Catalunya en 1995, seguidos de La Vanguardia en 1996, y el primer medio totalmente digital fue La Estrella Digital a partir del 9 de junio de 1998. En el primer lustro del siglo XXI los diarios digitales proliferaron, al tiempo que entraron en crisis los impresos por falta de rentabilidad.

Pedro J. Ramírez y Juan Luis Cebrián, según indica Rubén Arranz en Voz Populi ${ }^{4}$, afirmaron que: "La muerte del papel es irremediable". La Oficina para la Justificación de la Difusión (OJD) señala que en 2005 El País contaba con una difusión de 432.204 ejemplares, El Mundo con 330.634, ABC con 240.255 y La Razón con 142.838 , mientras que una década más tarde la media de El País era de $183.560, E l$ Mundo 105.407, ABC 86.570 y La Razón 75.677.

Entre 2008 y 2015 cerraron en España 375 medios. En lo que se refiere a diarios, según el Informe Anual de la Profesión Periodística (2016), se cerraron 38, de los que 26, es decir el 68,4\%, se clausuraron entre 2011 y 2013. En el mismo periodo, se registraron 579 nuevos medios digitales, de los que a finales de 2016 permanecían activos 458. Este fenómeno es similar al que se produjo en otros sectores, como el editorial, donde los profesionales apostaron por crear proyectos, dada su formación y experiencia. Los diarios locales cerrados han sido numerosos, y el Informe Anual de la Profesión Periodística señalaba en 2015 los problemas para mantenerlos (Tabla 1):

Tabla 1. Problemas para mantener un diario

\begin{tabular}{|l|l|l|}
\hline & Año 2014 & Año 2015 \\
\hline Descenso de la publicidad & 66,7 & 70,2 \\
\hline Financiación del proyecto & 66,7 & 56,1 \\
\hline
\end{tabular}

www.vozpopuli.com, 12/12/2016. 


\begin{tabular}{|l|l|l|}
\hline Falta de tiempo & 43,9 & 36,8 \\
\hline Falta de promoción. Problemas de marketing & 15,8 & 35,1 \\
\hline Falta de conocimientos de gestión empresarial & 31,6 & 31,6 \\
\hline Poca difusión, escasa audiencia & 21,1 & 26,3 \\
\hline La burocracia, dificultades administrativas & 21,1 & 17,5 \\
\hline Falta de entendimiento entre los socios & 7,0 & 8,8 \\
\hline Otros & 5,3 & 5,3 \\
\hline
\end{tabular}

Sobre la publicidad escribió Álvaro G. Zarzalejos (2017): "La Prensa de papel, en el chasis: La publicidad también caerá este año víctima de Internet", advirtiendo que el mercado publicitario se trasvasaba a la edición digital. El Libro Blanco de la Prensa (2016) afirma que el dinero de la publicidad ha pasado de la prensa en papel a los medios audiovisuales. En el mismo informe se indica que a partir de 2011 los diarios facturaron casi un $40 \%$ menos y sus beneficios cayeron más de un $80 \%$ hasta diciembre de 2015. Las cifras sobre el consumo de periódicos impresos y digitales eran que en 2009 el 77\% de los lectores lo hacían en papel, el 10,5\% en formato digital, en el año 2015 el 49,9\% seguían leyendo en papel y el 32\% en digital.

Uno de los activos de los diarios son sus archivos, no siempre puestos en valor lo que explica, en cierta medida, la desaparición (destrucción) de muchos de ellos. Un ejemplo del valor de la documentación generada por la prensa surge de los dominios, como en el caso de El Xornal, que en 2017 realizó una operación excepcional fundamentada en la referencia de los términos más utilizados y consultados en internet, en el número de visitas del periódico, y en su archivo documental, de contenido genérico y especialmente político y empresarial sobre Galicia.

En lo que se refiere a los contenidos y su conservación, el cambio hacia lo digital hizo creer que la recuperación de los materiales empleados o los documentos generados serían fácilmente consultables o accesibles, y que en consecuencia servirían para recuperar información y ponerla a disposición de los profesionales e investigadores. Hasta ahora no solo ha sido así sino que parece que sea un objetivo futuro.

\subsection{Versiones digitales}

Las versiones digitales se plantearon como solución al problema del papel. Un ejemplo fue Público, lanzado primero en papel pero que por falta de inversores hizo que Mediapubli lo cerrara en febrero de 2012 para dejar solo la versión digital. En el Estudio General de Medios (EGM) los resultados en cuanto a lectores presentaban el siguiente panorama en 2016: El diario Marca se situaba a la cabeza de los lectores, con 2.165.000, delante de El País (1.217.000), As (1.149.000) y El Mundo (761.000). Como se observa, el deporte continúa siendo el tema de mayor interés, sumando más de cuatro millones de lectores si añadimos a los dos anteriores Mundo Deportivo (466.000) y Sport (436.000). De igual forma la web de Marca, con 4.547.000 lectores, es la más visitada, seguida de As con 2.246.000, Sport con 1.281.000 y Mundo Deportivo con 1.195.000.

La Vanguardia ganó en junio de 2017 más de 1,4 millones de usuarios en su versión digital, al tiempo que El Mundo subía en 900.000 y el Huffington Post un millón. Este incremento significó la subida de las cifras en un 10\% para La Vanguar- 
dia, y se justificó en parte por el rediseño de la página web. En cuanto a El Mundo, las declaraciones de Pedro García Cuartango, son definitorias: «Un tipo de web con informaciones más en profundidad, con mucha menos información menos noticias y mucho más elaboradas» ${ }^{5}$. Realmente significativo, volver a la calidad en detrimento de la cantidad, es decir al «periodismo del papel».

En 2018 la prensa impresa y la digital se aproximan en número de lectores. En el 2000 se calculaban cinco años para que esto sucediera y pasó toda una generación. La desaparición de la prensa impresa no es un fin en sí mismo y por tanto los términos digital e impreso no deben entenderse como antagónicos. La cuestión es establecer los modelos de trabajo para que las diferentes instituciones públicas y privadas se conciencien del valor de la documentación, de su reutilización, y de su uso en la formación de la memoria histórica. En tiempos de la postverdad y de la puesta en duda de las informaciones es imprescindible el contraste de las fuentes y los datos. El futuro dependerá de muchos factores, por supuesto de los ingresos por publicidad, pero sobre todo de los contenidos y de los propios medios, que deben adaptarse a los cambios con total flexibilidad. La suerte no está echada, sino que fragua a golpe de profesionalidad. Y en todo ello es fundamental la conservación de la documentación.

\subsection{Blogs y redes}

En 2008 los blogs se incorporaron a la prensa, reservándose los temas específicos. $\mathrm{Su}$ presencia en los digitales se debe a la necesidad de acercarse a los lectores en el momento en que la prensa impresa perdía su peso específico. Los blogs o weblogs fueron definidos por Noguera (2008: 6) como anotaciones o diario personal en la red. El primer blog informativo en la prensa digital española lo publicó José Cervera, con el título "Retiario" en El Mundo, a comienzos de 2004. ABC, El Mundo, El País, La Razón y 20 Minutos presentaron los primeros blogs en 2005, que aumentaron considerablemente en muy poco tiempo, ya que en junio de 2010 seis diarios ( $A B C, E l$ Mundo, El País, La Razón, La Vanguardia y Público) sumaban 290 blogs, de los que 214 estaban activos y 76 inactivos o cerrados, con materias comunes en todos ellos: Cultura, Deporte, Economía, Sociedad, Comunicación y Tecnología.

La evolución fue constante y en 2015 El País contaba con 55 blog y ABC con 89 , con gran diversidad de contenidos y con una audiencia contabilizada en 20.691 y 19.346 entradas respectivamente. En esta cuestión hemos de considerar la calidad además de la cantidad, es decir el tipo de lector y el interés del mismo en los contenidos de los blogs.

En cuanto a las redes, Eric Qualman indicaba en 2011 que Facebook tenía mil millones de usuarios, por lo que el impacto sobre la prensa era obvio y en casos determinante. La vinculación de las redes a los medios la evidenció el periódico Financial Times al indicar que el $20 \%$ del tráfico en su web procedía de las redes sociales. Los lectores en este medio eran muy activos (el 90\%), con un seguimiento de más de dos millones en Twitter, un millón y medio en Google +, y medio millón en Facebook. Los medios han tratado de aprovechar sus valores, y una vez que todos las utilizan volvemos al punto de partida: ¿Qué se nos ofrece?, es decir: los contenidos. 
Las redes sociales más usadas en el mundo son Facebook, Youtube, Instagram y Linkedin. Twitter tuvo un descenso de usuarios en 2017. En España, el Estudio Anual de las Redes Sociales (2017) señala que cerca de veinte millones de internautas españoles utilizan las redes, con un crecimiento del 50\% hasta el $86 \%$ entre 2009 y 2017. Facebook y Twitter son las más mencionadas cuando se llevan a cabo consultas, y se consideran también Instagram y Linkedin. En lo que se refiere a la prensa, nos interesa la encuesta de New Reports.es (2017), en la que se indica que los medios tienen alta credibilidad sobre la información que publican (47\%), frente a las redes $(36 \%)$, aunque se considera que tienen alta influencia de los poderes políticos y económicos. Como señala Túñez (2012: 238): «Los medios usan las redes como nuevas audiencias para sus contenidos en la versión online. Cada uno ha marcado una estrategia diferente. Twitter se sitúa en la esfera pública de la comunicación informal y oficial, mientras que los contenidos de Facebook son de la esfera íntima».

\section{Las revistas}

Los teóricos han recurrido una y cien veces a la frase que Víctor Hugo puso en boca del personaje Claude Frollo en Notre-Dame de París: "Esto matará aquello". Se refería al impacto de la imprenta sobre la cultura y el arte. Pero aquello nunca mató esto, sino que lo reconvirtió, lo modificó o cambió, pero no lo eliminó, e incluso en algunos casos lo ha puesto en valor. El cierre de las revistas fue la crónica de una muerte anunciada desde que la televisión empezó a contar historias. Hasta los años sesenta del siglo XX no tuvieron competencia, aunque mucho antes de que las imágenes televisadas se apropiaran de su espacio, las ilustraciones se habían hecho imprescindibles.

No es objeto de este trabajo hacer un resumen histórico de la prensa, pero es inevitable citar a las más importantes revistas, como Life, creada por Henry Luce en 1936, y basada en el fotoperiodismo, que dejó de ser semanal en 1972. Sus portadas recogen la historia universal de cuatro décadas. En España el paradigma comenzó con La Ilustración Española y Americana en el siglo XIX, y con la inigualable Blanco y Negro a partir de 1891; en el primer tercio del XX apareció Mundo Gráfico entre las de información general, y de las culturales fue un referente La Esfera a partir de 1914 (Sánchez Vigil, 2008). Después de la guerra civil se creó en 1946 Triunfo, primero con contenidos teatrales y cinematográficos, y después generales. Fue el paradigma de la oposición a la dictadura en los años sesenta. Otro modelo emblemático fue Interviú, creada en 1976 y durante más de cuarenta años dedicada a la investigación.

El paso de las revistas en papel a digital fue lento, más que en los diarios. La creación de revistas digitales no fue garantía de éxito, así por ejemplo The Magazine, creada en 2013 por Marco Arment mediante suscripción y accesible desde la aplicación Quiosco de Apple, cerró con tan solo 53 números en la red. Este modelo, que parecía perfecto por sus contenidos de calidad y por su precio (1,99 dólares) no encajó en el mercado. El mismo proceso sufrió The Daily, en este caso con el apoyo económico de Rupert Murdoch, demostrando así que el paso del papel al digital en el caso de las revistas no era tan claro. En España, el Informe Anual de la Profesión Periodística (2016) señala que entre 2008 y 2015 se cerraron 214 revistas, el 59\% 
en 2012 y 2013. Si en 2008, una vez que la crisis invadió todos los sectores, sólo se cerraron 13, en 2012 el número se multiplicó por 5 hasta alcanzar los 66 títulos. Entre 2013 y 2014 se clausuraron otras 66 y en 2015 tan solo 4. En 2017, a pesar de la recuperación económica, siguieron cerrando, lo que venía a confirmar que el problema no era solo económico sino fundamentalmente estructural.

\subsection{La crisis de las clásicas}

Life es una referencia para entender la evolución de las revistas desde la segunda mitad del siglo XX hasta el periodo digital. Esta publicación, semanal en origen, reapareció hasta en siete ocasiones, después de su primer cierre en 1972. Fue mensual desde 1978, luego crónica gráfica de la guerra del golfo en 1990, monográfico especial hasta el 2000, y desde 2004 suplemento de los periódicos del grupo Tribune. Salió el 23 de noviembre de 1936 con un cuarto de millón de ejemplares que en apenas unos meses se multiplicaron por cuatro y en un año pasaron a ser millón y medio. Parte de su éxito se debió a las excepcionales fotografías. Su decadencia comenzó con la televisión, hasta que en 1972 fue cerrado por las fuertes pérdidas económicas.

Otro ejemplo modelo fue Parkett, dedicado a la creación artística desde 1984, con una tirada de 11.000 ejemplares en dos números al año y distribuida en 60 países. Su fundadora y editora, Vice Curiger, puso el broche a la revista con el número 100 , justificando la clausura con dos motivos: los nuevos hábitos de lectura, con preferencia a lo digital sobre el papel, y la progresiva desaparición de librerías independientes en todo el mundo. El coeditor de la revista, Dieter von Graffenried, explicaba a los lectores en el número de cierre (1984): "Parkett es un libro, un objeto analógico de 1,5 kilos, diseñado página a página. Y nos damos cuenta de que los lectores han abandonado radicalmente este mundo analógico y pasan casi todo su tiempo en el universo digital".

Entre las revistas españolas de información general ya desaparecidas un ejemplo es Panorama del Grupo Z, con fuerte impacto entre 1987 y 1993. Cerró por la saturación de semanarios de ese tipo en el mercado. Los motivos aludidos por los responsables fueron los problemas económicos. Una vez cerrada se decidió potenciar Interviú y Tiempo, las dos revistas más prestigiosas del grupo en aquella época. La tirada media de Panorama fue de 125.000 ejemplares con una venta de 52.000. Entre las tres citadas llegaron a copar el 68\% del mercado en 1990.

\subsection{La especialización}

A pesar de que los teóricos apostaron en principio por la especialización frente al impacto digital, la realidad ha sido y es bien distinta como veremos en los ejemplos seleccionados. La revista de contenido político La Clave, fundada y dirigida por José Luis Balbín, y con el aval del programa televisivo del mismo título, se mantuvo viva siete años entre 2001 y 2008 hasta que murió afectada por la crisis al no encontrar financiación. En el deporte Finisher Triatlon cerró en 2014 tras 18 años de rodaje, Transworld Surf, editada por GrindMedia, uno de los grandes grupos editoriales del mundo, lo hizo en junio de 2013 su versión en papel para lanzar los contenidos en digital. Jaque fue decana de las revistas dedicadas al ajedrez hasta julio de 2012, y los comentarios en la prensa sobre su cierre se basaron en la honestidad, en la cali- 
dad de contenidos y en el sentimiento, los mismos argumentos que en la mayoría de las revistas especializadas, aunque su responsable Yago Gallach puso el dedo en la llaga con esta frase: "Nos vamos todos a la mierda si el único futuro que nos queda es ofrecer y consumir productos gratuitos"6. Antes, en 2007, había quebrado Winner Tennis, y en 2014 lo haría Tenis World, basada en el impacto de las fotografías, de las que por otra parte estaba plagada la red.

En otro campo, también es significativo el caso de Zero, cuyo objetivo fue dar visibilidad al colectivo LGTB (Lesbianas, Gays, Transexuales y Bisexuales), y lo consiguió mientras se mantuvo en activo hasta que la crisis económica, es decir la falta de publicidad, acabó con el proyecto. Surgió en 1998, con una primera etapa gratuita, y se publicaron 120 números hasta diciembre de 2009. En 2006 alcanzó una difusión de 26.518 ejemplares, según la Oficina de la Justificación de la Difusión, con una tirada de 50.000 .

Incluso las temáticas relacionadas con la tecnología, como PlayStation editada por el Grupo Zeta, cerró en diciembre de 2012, después de 12 años y 144 números, siguiendo la estela de otras como PC Wordl, iPhoneworldy TechStyle. En julio de 2013 cayó $P C$ Actual después de un cuarto de siglo en los quioscos. Salió en 1988 y la venta superó los 93.000 ejemplares en 1999. En 2012, sin embargo, solo se vendían 33.000. En 2014 cerró su versión en papel Macworld, dependiente de International Data Group (IDG).

El tema de las revistas culturales es paradigmático. Archipiélago suspendió su publicación por problemas económicos en 2009 tras veinte años de existencia. Babylon Magazine, duró seis años entre mayo de 2008 y abril de 2014 con el objetivo de llevar la cultura española al resto de Europa. La dirigió Juan Calleja y se difundió gratuitamente, en edición bilingüe, con una tirada media de 30.000 ejemplares en los Centros Culturales. El Punto de las Artes justificó su caída por la publicidad, tras 22 años de publicación semanal. Salió el 14 de abril de 1986 y se editaron 938 números. Parece claro que en este caso las webs de los propios centros (museos, salas de exposiciones, etc.) han influido en la quiebra.

Entre las culturales, Revista de Libros fue editada por la Fundación Caja Madrid hasta 2013, y desde entonces con el patrocinio de la Obra Social La Caixa su objetivo era transmitir opinión cultural a un público formado. Cerró la edición en papel en 2011, aunque había comenzado la andadura digital en 2008, primero con acceso restringido y más tarde abierto desde el primer número de 1996. En su archivo cuenta con un fondo de más de 4.000 artículos y 15.000 reseñas realizadas por más de un millar de colaboradores. Otra clásica fue Delibros, creada en mayo de 1998 y cerrada con 282 números en enero de 2014. El Cuaderno, editada por Trea, salió en octubre de 2011 como semanal de cultura de La Voz de Asturias, sin costo para el consumidor. Tuvo un primer formato, profusamente ilustrado, una segunda etapa trimestral en 2015 con más de un centenar de páginas, y la versión digital a finales de 2016.

Otro modelo específico son las de fotografía. Arte Fotográfico, fundada en enero de 1952 y cerrada en 2015 con el número 642. En 2012 salió Af.es en un intento de recuperar la publicidad perdida en Arte Fotográfico. Enriquecida en contenidos, de calidad excepcional y con un proyecto de futuro, no tuvo respuesta. La gratuidad de contenidos arrastró en este caso a la calidad y al trabajo elaborado. 


\subsection{Una mirada al futuro}

La vuelta al papel es un hecho en determinados casos. Como ejemplo la revista cultural Ajoblanco, con amplio reconocimiento e historial, editada por la Asociación Cultural Ajoblanco formada por Pepe Ribas, Carolina Espinoza y Fernando Mir. Su origen se remonta a 1974 y tuvo una primera etapa durante la Transición política hasta 1980, y una segunda entre 1987 y 1999 coincidiendo con el cambio digital. Entonces llegó a vender cien mil ejemplares, con cerca de dos millones de lectores. Ajoblanco se reinventa como una respuesta a la irreflexión, derivada de la inmediatez y propone un cambio, otra forma de mirar, manteniendo los esquemas clásicos. Este es el ejemplo en el mundo cambiante donde el interesado en los contenidos colabora mediante el crowdfunding, con el que la revista consiguió 37.000 euros para poner en marcha el proyecto.

Sus contenidos son sobre cine, literatura, feminismo, ecología y ciencia. La periodicidad es trimestral en España y Latinoamérica, con 50.000 ejemplares de tirada y 132 páginas sin publicidad: "Queremos revitalizar la cultura desde la pasión, el respeto, la pluralidad, la imaginación, el humor, la crítica, el debate, el diálogo y el encuentro. Queremos transgredir los límites. Salir del letargo y perder el miedo que nos ha atenazado durante demasiado tiempo. Necesitamos un pensamiento nuevo, libre, sin cánones impuestos y sin burbujas, donde las generaciones, las culturas, las ciudades y las identidades dialoguen, se mezclen y se expandan. Queremos recuperar la memoria, hurgar donde otros temen hacerlo y plantear todo lo necesario para sentirnos vivos"7. Pepe Ribas, director de la publicación, manifestó que los motivos para lanzar la revista en papel son la distribución más libre y un nuevo tipo de lector que busca un modelo nuevo no ideologizado (Rodríguez Veiga, 2017).

El futuro, en lo que se refiere a la conservación de la documentación de la prensa es incierto. Aquellas publicaciones impresas sin rentabilidad económica desaparecerán paulatinamente, o bien se transformarán en ediciones digitales. Los grandes grupos no han encontrado el nicho para las revistas, ni impresas ni digitales, con cierres de cabeceras tan emblemáticas como Interviú.

El futuro no es solo el cierre sino también la reconversión, y en ello juega un papel fundamental la publicidad y las subvenciones. Este aspecto es clave en el tema que tratamos, porque una condición para la subvención debería ser el compromiso de la entrega de la documentación generada en caso de cierre, una forma de conservar el patrimonio.

\section{La prensa gratuita}

La Asociación Española de Prensa Gratuita (AEPG) define en sus estatutos (art. 2.2) a la prensa de distribución gratuita como: "Publicaciones que se distribuyen gratuitamente y no representan (sic) ninguna contraprestación económica por parte de los lectores, que tengan una periodicidad no superior a un mes, que dispongan de un control de distribución, que se editen en territorio español, que incluyan información general y que estén formadas por un contenido redactado de elaboración propia de 
al menos un 30\%. La información que difundan deberá ser de interés local y comarcal y será escrita en la lengua propia de cada comunidad, con voluntad explícita de defensa de esa lengua"

El origen de las cabeceras gratuitas data de 1995, cuando Metro Internacional, filial de Modern Times Group (MTG), inicia la distribución gratuita de Metro en el transporte público de Estocolmo. En 1999, la noruega Schibsted lanzaría 20 Minutos en Zúrich. A España llegaría en el año 2000 experimentando una expansión sin precedentes y cuya rápida aceptación demostró que existía una demanda latente de este tipo de medios. Los diarios de pago y los gratuitos comparten el mismo modelo de negocio basado en la publicidad y compiten por los mismos mercados. La característica de la prensa gratuita se encuentra en el control de la distribución directa de sus ejemplares por el editor.

\subsection{Madridym@s, 20 Minutos, Metro, Qué! y ADN}

La primera publicación gratuita en España fue Madrid $y m @ s$ fundada en febrero de 2000 por Arsenio Escolar Ramos y José Antonio Martínez Soler, y editado por Multiprensa y Más. El 16 de noviembre de 2000 se lanzaba la edición de Barcelona, Barcelonaym@s, también con 100.000 ejemplares y una ocupación de mancha publicitaria del 30\%. Un año después 20 Min Holding (Grupo Schibsted) compraría la mayor parte de las acciones de la empresa editora, lo que supuso un cambio de nombre del periódico: 20 Minutos, marca del grupo noruego en otros países donde estaba presente. A partir de entonces, el diario tuvo un proceso de expansión hasta tener ediciones en 15 capitales españolas. En 2007 se convirtió en el periódico más leído de España tras superar a Marca, y en 2008 batió el récord de lectores diarios, con cerca de tres millones.

En 2003 aparecen 20minutos Sevilla y Zaragoza, y en 2004 Valencia y Alicante. Pero será en 2005 cuando el diario alcanza su máxima expansión, con la incorporación de nuevas ediciones en Asturias, Bilbao, Córdoba, Granada, La Coruña, Málaga, Murcia, Valladolid y Vigo. En solo cinco años, 20minutos se convirtió en el diario más leído en España, según el Estudio General de Medios (EGM) con un récord absoluto de lectores de un diario de información general en España, con 2.911.000 de media diaria.

En 1999 el grupo editor de Metro realizó los primeros sondeos e intentar lograr acuerdos con las autoridades de los metros de Madrid y Barcelona. Metro de Barcelona, de titularidad municipal, decidió lanzar un concurso público para editar un diario gratuito copiando el modelo de Metro, pero que contemplaba la exclusiva en la distribución. Al concurso se presentaron el Grupo Godó, editor de La Varguardia junto con Modern Times Group (MTG), editor internacional de Metro; y el Grupo Zeta (El Periódico de Catalunya), aliado con el grupo noruego Schibsted. El concurso se declaró desierto, por lo que la salida de Barcelona y m@s y la presencia de Schibsted, aliado del Grupo Zeta, precipitaron la salida sin socios de la cabecera de Metro Internacional en Barcelona el 5 de marzo de 2001 con el título Metro Directe y 190.000 ejemplares de tirada. Metro Directo salió en Madrid el 27 de agosto de ese año, con 24 páginas y 250.000 ejemplares.

Qué! y $A D N$ salieron en 2005 y 2006 respectivamente. El primero editado por el Grupo Recoletos y el segundo por el grupo Planeta. Qué! lanzó doce ediciones en 
trece ciudades, con una tirada inicial de un millón de ejemplares en 7.500 puntos de distribución. El 18 de julio de 2007 se lanzaba el portal ADN.es que aunaba las distintas ediciones de la versión impresa, y recogía noticias de interés para aquellas regiones donde aún no se editaba. Tenía una actualización constante, ofrecía archivos multimedia que complementaban la información escrita y la posibilidad de personalizar la web.

En 2007 Vocento haría una gran apuesta por el diario Qué! y acometió una serie de medidas para reducir costes y acelerar la integración del diario en el grupo. El resultado fue el cierre de delegaciones para centralizar sus ediciones en Madrid y Barcelona. En 2010 quedaban operativas las ediciones en Aragón, Asturias, Barcelona, Bilbao, Castellón, La Rioja, Madrid, Málaga, Sevilla y Valencia.

\subsection{Crisis del sector}

La caída de ingresos publicitarios fue el motivo del cierre de los gratuitos. Metro fue el primero en 2009, en 2011 ADN, y Qué! en 2012. El único diario que se mantuvo fue 20 minutos, bajo la propiedad de Heraldo a partir de 2015. Desde 2007 las tres cabeceras 1,375 millones de lectores según el EGM, lo que suponía una caída de lectores del 23,4\% en sólo cuatro años.

En 2011, los datos de la Oficina de Justificación de la Difusión de medios en Internet (OJD Interactiva) consolidaban a 20minutos.es como uno de los líderes en el mercado de prensa digital con un total de 13.730.204 usuarios únicos y 27.837.505 visitas en marzo de 2011. El Grupo 20minutos lanzó además otros productos como magacines y guías personalizadas de gran interés para el lector: El Mensual (2012) con reportajes, entrevistas y estilo de vida y MiBolsillo (economía) en 2013, y aplicaciones como: Fútbol20 (2012); el portal Tiempoytemperatura.es (2011) y Gonzoo. com (2013).

En julio de 2013, Qué! pasó a formar parte del Grupo Gestiona (Revista Capital, Gestiona Radio, la Revista Subastas del Siglo XXI y Diario Financiero) y vuelve a salir a la calle el 5 de diciembre de 2014 -en plena crisis de los medios impresos- liderado por Borja Nocito y Alejandro Suárez Sánchez-Ocaña. Actualmente la publicación es carácter semanal y sale todos los viernes en Madrid y Móstoles.

20 minutos, además de ser el pionero, ha conseguido grandes hitos para la historia de la prensa española creando millones de lectores en un país con bajísimos índices históricos de lectura de prensa. A comienzos del año 2015, los datos publicados por Schibsted señalaban que había registrado unas pérdidas operativas (Ebitda, arnings Before Interest, Taxes, Depreciation, and Amortization) acumuladas de 18,6 millones de euros desde 2011, por lo que fue vendido al Grupo Heraldo, que reforzó y consolidó el proyecto. Entre 2015 y 2017 la distribución fue en torno a los 300.000 ejemplares.

\section{La prensa en las hemerotecas}

Hasta la implantación del Depósito Legal gran parte de las publicaciones se guardaron en centros privados cuya desaparición ha originado la dispersión cuando no la destrucción de diarios y revistas. La Ley de Depósito Legal (2011) incluye el 
patrimonio hemerográfico dentro del bibliográfico, considerado uno de los más ricos y representativos del mundo. En el artículo 3 del capítulo I se definen tres tipos de publicaciones: electrónica, periódica y seriada, diferenciando las dos últimas en la numeración y la falta de duración predeterminada en la seriada.

Desde los inicios de Internet hasta finales del siglo XX la mayoría de los diarios disponían de una hemeroteca testimonial, modificada y ampliada posteriormente hasta alcanzar las posibilidades de hoy. Obviamente, los diarios nacidos digitales han construido las hemerotecas digitales en paralelo al desarrollo de la publicación. Se trata de servicios específicos del entorno digital y diferenciados claramente de las ediciones impresas que ofrecen los diarios y agencias de prensa a los usuarios. Forman parte de lo que se conoce como Servicios Documentales de Valor Añadido (SDVA) y ofrecen como ventajas el aumento del número de usuarios, oferta completa del fondo y consulta en línea desde cualquier punto. Actualmente, los servicios permiten consultar todo tipo de información periodística, actual o retrospectiva, de las ediciones digitales o de las impresas, tanto los textos como las fotografías o los vídeos.

Toda la prensa de tirada nacional ha desarrollado programas de actuación y digitalización en esta línea, como la hemeroteca del diario El País (https://elpais.com/ archivo) creada en 1996 y en cuyo archivo se pueden encontrar los contenidos publicados en la edición impresa desde su primer número del 4 de mayo de 1976 hasta la actualidad; y El Mundo (http://elmundo.es/hemeroteca) que permite la consulta de fondos desde el año 1994.

Algunos casos resultan extraordinarios por la cantidad y calidad de los contenidos, como los casos de Abc y La Vanguardia. Creada en 2009, la hemeroteca de $A b c$ (http://hemeroteca.abc.es) contiene entre quince y veinte millones de artículos y unos cinco millones de páginas digitalizadas (noticias y fotos) e incluye Blanco y Negro, el diario Abc desde 1903, y los contenidos de todos los suplementos. En la hemeroteca de La Vanguardia (http://www.lavanguardia.com/hemeroteca), son consultables textos e imágenes desde finales del siglo XIX. Otro de los valores de la digitalización de fondos es la preservación y conservación de las colecciones originales, que permiten contextualizar contenidos, asociarlos a otras noticias y/o secciones e incluso a fotografías.

En el caso de la prensa de distribución gratuita, una vez desaparecidas las cabeceras poco o nada se sabe del destino de sus archivos y hemerotecas, si bien es de suponer que los conservan los grupos de comunicación que los compraron: Recoletos, Vocento, Gestiona y Planeta. Salvo el diario 20minutos, apenas han dejado rastro en la web. La página de inicio del diario del grupo Heraldo ofrece entre sus servicios la consulta al archivo (http://www.20minutos.es/archivo), con una cobertura que abarca desde enero de 2005 hasta la actualidad.

Fruto de la importancia y complementariedad de la prensa gratuita y online la Asociación Española de Prensa Gratuita pondría en marcha en 2009 un área digital para las ediciones digitales de sus publicaciones y otras que sólo son online. En 2015 se lanzaba el ambicioso proyecto turevistero.com, con el objetivo de compilar todas las revistas gratuitas en español en una sola web, agrupadas en distintas categorías, desde actualidad hasta moda, pasando por música y ocio, proyecto que lamentablemente ya no es accesible.

El actual desarrollo de Internet y la tendencia al menor consumo de papel, gran parte de la prensa se encuentra gratuitamente online, medio que facilita la lectura 
de noticias desde cualquier dispositivo y en cualquier lugar. Muchos diarios se han integrado dentro de las tabletas, con plataformas como Orbyt (http://quiosco.orbyt. es), quiosco digital multisoporte del grupo Unidad Editorial, con diarios como $E l$ Mundo, Marca y Expansión y revistas como Telva, Actualidad Económica, Marca y Motor, entre otras. La suscripción al servicio ofrece la consulta al catálogo de publicaciones, la descarga automática de las publicaciones con el formato tradicional adaptado a todo tipo de dispositivos (Tablet, móvil, ordenador...) y el acceso sin conexión. Además ofrecen contenido enriquecido como imágenes y vídeos exclusivos. Permite compartir artículos por email o redes sociales, el acceso gratuito a la hemeroteca y a todos los suplementos del periódico. Las cabeceras de Vocento, Prisa o Zeta han hecho lo propio con Kiosko y más (https://www.kioskoymas.com). Kiosko. net (Kiosko.net) es otra plataforma que sirve de puerta de entrada a los principales periódicos del mundo, entre ellos al diario gratuito 20minutos.

La prensa ha seguido un proceso de convergencia en el que el papel ha cedido paso al teléfono móvil y a las nuevas plataformas. Parece imprescindible reconvertir el negocio a las nuevas demandas del mercado y seguir la pista a los lectores en el proceso de migración del papel a la web, para permitir a los anunciantes llegar al consumidor. Sin embargo, la cantidad de contenidos que se generan en soporte digital, lo efímero de su permanencia y su importancia como fuentes de información para el futuro obliga a asegurar su preservación y transmisión.

\section{El Archivo de la Web Española}

Enmarcado en el Plan de Servicios Públicos Digitales de la Agenda Digital para España, este proyecto consiste en la creación de un portal desde el acceder a la colección formada por los sitios web archivados (incluidos blogs, foros, cuentas de Twitter, imágenes, vídeos, etc.) siempre que contengan patrimonio bibliográfico, sonoro, visual, audiovisual o digital de las culturas de España.

Desde 2011, los sitios web y las publicaciones en línea son considerados objeto de depósito legal (Ley 23/2011, de 29 de julio, de depósito legal), y como tal la BNE y los centros de conservación de las Comunidades Autónomas tienen la obligación de preservarlos como parte de sus colecciones patrimoniales. La Biblioteca Nacional de España tiene entre sus funciones actuar como centro depositario y de conservación de la producción cultural española en cualquier soporte, que incluye los documentos electrónicos y sitios web, además de garantizar el acceso y la recuperación de toda la información sobre el patrimonio bibliográfico y documental.

La obligación de los editores y productores de contenido en línea se limita a dejar que los centros de conservación recolecten sus publicaciones o a facilitar el depósito cuando estos lo soliciten. El acceso a las publicaciones ingresadas por esta vía debe respetar la legislación en materia de propiedad intelectual y de protección de datos de carácter personal.

El Archivo web y depósito legal electrónico en la Biblioteca Nacional se puso en marcha a finales de 2009, por acuerdo con Internet Archive para la realización de recolecciones masivas de páginas y sitios web españoles albergados en el dominio .es, y en otros dominios y subdominios genéricos: .com, .edu, .gob, .org, net, etc. Las recolecciones buscan reproducir con detalle el aspecto del sitio y las funcionali- 
dades del mismo disponibles durante la captura, de tal forma que la réplica del sitio web sea tan navegable como su versión viva. Una vez realizado el rastreo, las webs archivadas son visualizadas en la aplicación que ofrece al usuario la posibilidad de seleccionar qué versión concreta de un sitio web desea consultar.

La gran cantidad de información en Internet dificulta, o más bien imposibilita, la exhaustividad del archivado web, por lo que se ha optado por la recolección masiva y selectiva, siguiendo la pauta de otras bibliotecas nacionales de los principales países del mundo.

\section{Conclusiones}

La irrupción de la prensa digital a partir del siglo XXI asestó un duro golpe al papel, de carácter irreversible. El cierre de las empresas provocó la pérdida de su patrimonio, total o parcial, sobre todo de las publicaciones especializadas. Sin embargo, la prensa digital tampoco se salvó de la quema, sobre todo las revistas, porque debido a la crisis económica mundial la fuente de ingresos procedente de la publicidad descendió considerablemente.

El valor patrimonial de la prensa está en sus contenidos pero también en el continente. A pesar de los numerosos e importantes estudios de diarios y revistas en forma y fondo, resulta significativo que, salvo las excepciones de las grandes cabeceras, continúen perdiéndose archivos de publicaciones de relevancia. No obstante, las instituciones públicas encargadas de la conservación del patrimonio han llevado a cabo una labor excepcional mediante la creación de las hemerotecas digitales que ponen a disposición del usuario una ingente cantidad de información. Es el caso de la Hemeroteca Digital de la Biblioteca Nacional de España.

En lo que se refiere a la actuación de las propias empresas de comunicación, es destacable la creación de hemerotecas que más allá de su función particular realizan una función pública mediante la prestación de servicios a los investigadores y a la comunidad científica. Es el caso, como ejemplo, de las hemerotecas de La Vanguardia (1881) o $A B C$ (1905). Este último recoge información desde 1891, año de creación de la revista Blanco y Negro.

Tras la investigación realizada, se concluye que deberían establecerse normativas o protocolos que obligaran a las empresas de comunicación a depositar, además de los ejemplares, la documentación relacionada con los contenidos en las instituciones habilitadas para ello. De esta forma se garantizaría su posterior tratamiento y en consecuencia su difusión.

En lo que se refiere a las publicaciones digitales, de acuerdo a la Ley de Depósito Legal 23/2011, cabe destacar la puesta en marcha del Archivo de la Web Española por la Biblioteca Nacional de España, cuyo marco es el Plan de Servicios Públicos Digitales de la Agenda Digital para España, un portal dedicado a la preservación del patrimonio bibliográfico, sonoro, visual, audiovisual o digital de las culturas de España, procedente también de blogs, foros, imágenes, vídeos, etc. 


\section{Bibliografía}

Angeletti, Norberto y Oliva, A. (2002). Revistas que hacen e hicieron historia. Madrid: Sol 90 Media.

Arroyo Cabello, M. (2006). “La prensa gratuita ¿Un nuevo modelo informativo? Prensa y Periodismo Especializado”. III Congreso Prensa y Periodismo Especializado, Guadalajara.

Casero Ripollés, A. (2002). Diarios gratuitos: la calidad informativa en tela de juicio. Revista Latina de Comunicación Social, 5, mayo.

Cerezo Gilarranz, J. (Director, 2009). La revolución de la prensa digital. Cuadernos Evoca Comunicación, 1. Madrid: Evoca Comunicación e Imagen.

Delgado Barrera, A. (2009). Quince años de prensa digital en España, en Cerezo Gilarranz, J. (Director, 2009). La revolución de la prensa digital. Cuadernos Evoca Comunicación, 1. Madrid: Evoca Comunicación e Imagen, 11-15.

Estudio General de Medios (2016). Asociación para la Investigación de Medios de Comunicación. www.aimc.es/-Datos-EGM-Resumen-General.html [consulta: 1 de junio de 2018] .

Flores Vivar, J.; Mirón López, L. (2009). Prensa gratuita y calidad informativa: innovaciones tecnológicas, retos y perspectivas en los medios gratuitos. Apuntes y propuestas de metodologías y estándares de calidad para un nuevo modelo informativo. Madrid: Ediciones FIEC.

Gómez Quijano, A. (2016). La prensa más cara del mundo. Historia de los diarios gratuitos españoles.Madrid: Fragua

Informe Anual de la Profesión Periodística (2016). Madrid: Asociación de la Prensa de Madrid. http://www.apmadrid.es/publicaciones. [consulta: 1 de junio de 2018]

Libro Blanco de la prensa (2016). Madrid: Asociación de Editores de Diarios Españoles

Martínez Guillén, J. (2011). Saturación publicitaria en la prensa de distribución gratuita en España [tesis doctoral]. Madrid. Universidad Complutense.

Martínez Soler, José A. (2006). "La prensa gratuita de calidad y la profesión periodística. 20 Minutos" que cambiaron nuestro mundo". Informe Anual de la Profesión Periodística 2005. Asociación de la Prensa de Madrid, 2006.

Noguera Vivo, J. M. (2008). Blogs y medios: las claves de una relación de interés mutuo. Madrid: Libros en Red, 2008. http://www.esnips.com/doc/e6e0a76d-5921-4819-910f247b4cd9041/blogsymedios_2008. [Consulta: 10 de noviembre de 2017]

Núñez, Juan Carlos (1993). "El Grupo Z cierra por razones económicas la revista Panorama", en El País, 31 de agosto, p. 27.

Ramón, Manuel de (2009). "Diarios Gratuitos: los modernos refugios de la prensa popular en España” enPrensa Gratuita y Calidad Informativa. Ediciones FIEC. Madrid

Remón, Sandra (2006). "El irresistible ataque de los gratuitos a la prensa de pago", Periodista digital, 24 de marzo de 2006. Disponible en:http://blogs.periodistadigital.com/periodismo.php/2006/04/24/el irresistible ataque de los gratuitos

Rodríguez Veiga, Diego (2017): “Así sabe el primer Ajoblanco del siglo XXI”, en El Mundo, 22 de junio. En línea: http:://elmundo.es/cultura/2017/06/22/594b1c246163f7c438b4615. html [Consulta: 10 mayo de 2018]

Sánchez Vigil, J. M. (2008). Revistas ilustradas en España. Gijón: Trea.

Túñez López, M. (2012). Los periódicos en las redes sociales: audiencias, contenido, interactividad y estrategias comerciales. Estudios sobre el mansaje periodístico, 18, 1, 221-239.

Zarzalejos, Álvaro G. (2017). “La Prensa de papel en el chasis: La publicidad también caerá este año víctima de Internet”, en El Confidencial. https://www.elconfidencial.com/comunicación/2017/02/19. Consulta: [5 de mayo de 2018] 